\title{
Risky substance exposure during pregnancy: a pilot study from Lebanese mothers
}

\author{
This article was published in the following Dove Press journal: \\ Drug, Healthcare and Patient Safety \\ 14 May 2013 \\ Number of times this article has been viewed
}

\author{
Samar Rachidi' \\ Sanaa Awada' \\ Amal Al-Hajje' \\ Wafaa Bawab' \\ Salam Zein' \\ Nadine Saleh ${ }^{1,2}$ \\ Pascale Salameh ${ }^{1,2}$ \\ 'Laboratory of Epidemiological and \\ Clinical Research, Lebanese University, \\ Beirut, Lebanon; ${ }^{2}$ Faculty of Public \\ Health Lebanese University, Beirut, \\ Lebanon
}

Background: The harmful effects of medication and licit substance use during pregnancy may potentially constitute a major public health concern. Our study aims to assess risky exposure of Lebanese pregnant women to drugs, tobacco, caffeine, and alcohol, and to determine their effect on postnatal outcomes.

Methods: Women at term were addressed after delivery in five university hospitals of Beirut and Mount Lebanon between February and June 2012. A standardized questionnaire was administered to them. Moreover, medical files of both mothers and their respective newborns were checked to confirm information given by mothers, and to assess the health outcome of the babies.

Results: Among the interviewed 350 women, active and passive smoking of tobacco (cigarette or water pipe), and consumption of category $\mathrm{C}, \mathrm{D}$, and $\mathrm{X}$ drugs were common during pregnancy in Lebanon; they were shown to negatively affect the neonatal outcome in multivariate analyses: they significantly decreased Apgar scores and increased the risk of underweight and medical complications of babies $(P<0.05)$.

Conclusion: Our study demonstrated that Lebanese women were exposed during pregnancy to multiple medications and licit substances that affected the neonates' health. Our findings have implications for clinical obstetric practice and prevention programs in Lebanon. Efforts should be made to decrease exposure to harmful substances during pregnancy.

Keywords: pregnancy, smoking, cigarette, water pipe, caffeine, alcohol, drugs, Apgar score

\section{Introduction}

Every year, more than 9 million babies die in utero or in the first few weeks of life, and the majority of these deaths occur in developing countries, where teratogens play a major role. ${ }^{1}$ In fact, the term "teratogen" is used to designate products with teratogenic potential at clinical doses used in humans. ${ }^{2}$ It indicates an exposure to a physical or chemical agent that can interfere with normal development of cells and tissues and results in abnormalities and malformations in newborns. ${ }^{3}$ Currently, reproductive toxicologists consider the four major manifestations of abnormal fetal development to be growth alteration, functional deficit, structural malformation, and death. ${ }^{4}$ Teratogenicity can be triggered by many materials, such as medications and licit substances like alcohol, caffeine, and tobacco. ${ }^{3}$

Despite the lack of information on the safety of drug use during pregnancy, most pregnant women will likely be exposed to drugs. Indeed, fetal exposure can occur either before or after a woman knows she is pregnant. Many epidemiological studies have demonstrated that using drugs is associated with an increased risk of
Correspondence: Pascale Salameh Laboratory of Epidemiological and Clinical Research, Faculty of Pharmacy, Hadath Campus, Lebanese University, Beirut, Lebanon

Tel +96I 5463367

Email psalameh@ul.edu.lb 
birth defects, ${ }^{2}$ depending on types, timing, frequency, intensity, and duration of exposure. ${ }^{2}$

On the other hand, exposure to smoke, coffee, and alcohol during pregnancy can contribute to perinatal complications and poor neonatal outcomes, consequences that have been well identified in epidemiological studies. Effectively, maternal smoking during pregnancy is an established risk factor for miscarriage, perinatal mortality, low birth weight, premature births, and small babies. ${ }^{5-9}$ Despite the risks, many women still smoke during pregnancy: 17\% in England and Wales, ${ }^{10}$ and $14 \%$ in the US. ${ }^{11}$ In Lebanon, a study conducted by Chaaya and collaborators showed that pregnant women were partially knowledgeable about the health risks of cigarette and water-pipe smoking, and they had permissive attitudes towards all forms of smoking. Moreover, almost one-quarter (23\%) of participants reported smoking during pregnancy, with $17 \%$ smoking only cigarettes, $4 \%$ smoking only water pipe, and $1.5 \%$ smoking both. ${ }^{12}$ Smoking is responsible for $15 \%$ of all preterm births and increases the risk of perinatal mortality threefold. ${ }^{13}$

Although caffeine has been demonstrated to produce birth defects and fetal mortality in animal models, its effects in humans at normal levels of consumption are much less certain. A high level of coffee consumption is however associated with an increased risk of fetal death; it was linked to various adverse pregnancy outcomes, including fetal loss, birth defects, and fetal growth retardation. ${ }^{14}$ Finally, drinking alcohol during pregnancy can cause miscarriage, premature birth, stillbirth, low birth weight, ${ }^{15}$ and a range of lifelong disorders, known as fetal alcohol spectrum disorders. ${ }^{16}$ The most known, fetal alcohol syndrome, is one of the leading known preventable causes of mental retardation and birth defects. ${ }^{16}$ To our knowledge, no data exist about exposure of pregnant women to these substances in Lebanon.

While the harmful effects of different medications and licit substance use during pregnancy may potentially constitute a major public health concern worldwide, few epidemiological studies have examined the actual prevalence of risky substance exposure during pregnancy and its relation to perinatal problems in Lebanon. These data are important when making recommendations to health-care providers on screening substance use during pregnancy and for helping pregnant women to avoid these substances. Therefore, this study aimed to assess risky exposure of pregnant Lebanese women to drugs, tobacco, caffeine, and alcohol; a secondary objective was to assess their effect on postnatal outcomes.

\section{Materials and methods Population and data collection}

Consecutive delivering women at term were addressed after delivery in five university tertiary care hospitals of Beirut and Mount Lebanon between January and June 2012; one of the hospitals was public, while the four others were private. After oral informed consent, women were interviewed faceto-face by trained interviewers (interviewers were sixth-year pharmacy interns). We note that preterm delivering women, complicated pregnancies, and women with non-singleton fetuses were excluded from the study.

One day after delivery, women were told about the objective of the study, which was to describe their exposures to and consumption of different substances during pregnancy. Anonymity and confidentiality of the results were ensured, but no incentive was given for participants.

A standardized questionnaire was administered to them, inquiring about the following characteristics and exposures during pregnancy: sociodemographic characteristics, parity, medical problems before and during pregnancy, drugs and supplements taken during pregnancy, exposure to water-pipe and cigarette smoking (active and passive smoking), and consumption of alcohol, caffeine, and caffeinated beverages.

Moreover, medical files of both mothers and their respective children were checked to confirm information given by mothers, and to assess the health outcome of the babies until hospital discharge: weight, height, cranial perimeter, appearance, pulse, grimace, activity, and respiration score (Apgar score) at 5 and 10 minutes, and the presence of a medical problem requiring transfer to the neonatal care unit (NCU). For Apgar score, each of the five criteria is scored from 0 to $2: 2$ is reserved for strictly normal states, 0 for major anomalies, and 1 for all intermediate states. The normal newborn has an Apgar score greater than 7 at 5 and 10 minutes of life. ${ }^{17}$

\section{Definitions and classification}

Exposure to drugs was firstly assessed by drug name, and further classification was performed according to FDA classification of drugs during pregnancy: ${ }^{18}$ category A (adequate and well-controlled studies have failed to demonstrate a risk to the fetus in the first trimester of pregnancy, and there is no evidence of risk in later trimesters), category B (animal reproduction studies have failed to demonstrate a risk to the fetus, and there are no adequate and well-controlled studies in pregnant women), category $\mathrm{C}$ (animal reproduction studies have shown an 
adverse effect on the fetus, and there are no adequate and well-controlled studies in humans, but potential benefits may warrant use of the drug in pregnant women despite potential risks), category $\mathrm{D}$ (there is positive evidence of human fetal risk based on adverse reaction data from investigational or marketing experience or studies in humans, but potential benefits may warrant use of the drug in pregnant women despite potential risks), and category X (studies in animals or humans have demonstrated fetal abnormalities and/or there is positive evidence of human fetal risk based on adverse reaction data from investigational or marketing experience, and the risks involved in use of the drug in pregnant women clearly outweigh potential benefits). ${ }^{18}$ Drugs with mixed categories were classified according to the higher level of risk.

Smoking, caffeine, and alcohol exposure were assessed by a dichotomous variable of yes/no exposure; in the case of a positive answer, mean frequency of exposure was assessed. For neonates, weight at birth, Apgar score at 5 and 10 minutes after birth, ${ }^{19}$ and health problems that required transfer to the NCU were evaluated (fever, infection, respiratory distress, and severe hyperbilirubinemia). Babies were considered underweight if their birth weight was lower than $2750 \mathrm{~g}$; this broader definition than the usual one was adopted because of the low number of babies with birth weight $<2500 \mathrm{~g}$.

\section{Statistical analysis}

Data entry and analysis were performed using SPSS version 18.0 (IBM, Armonk, NY, USA). For Apgar score at 5 and 10 minutes, a transformation into logarithmic function to allow for a normal distribution of these variables was performed. Percentages were shown for qualitative variables, while means and standard deviation were given for quantitative variables. The chi-squared test was used to compare between-group percentages, while Student's $t$-test or analysis of variance were used to compare means between two or more groups, respectively. Missing data were not replaced.

Furthermore, multivariate analyses were performed: a multiple linear regression when the dependent variable was quantitative (Apgar scores for 5 and 10 minutes, and a logistic regression when the dependent variable was dichotomous [underweight baby, medical problem that required transfer to the NCU]). Backward stepwise models were retained, after ensuring models' adequacy using appropriate methods (normality of residuals for multiple regression and Hosmer-Lemeshow test for logistic regression).
Probabilities were used for stepwise removal $(P=0.10)$ and for stepwise entry $(P=0.05)$. Independent variables were age of the mother, geographical origin, body mass index before pregnancy, education level, occupation, parity, delivery type, medical problem types during pregnancy, weight gain during pregnancy, number of live children, delivery term, and exposure to medications and licit substances. The absence of collinearity between factors was checked by verifying the correlation coefficient of items and the variance inflation factor of retained items, which remained lower than 10 .

\section{Results \\ Description of the sample}

Among 367 consecutive delivering women who were approached, 350 (95.4\%) agreed to participate; nonresponders expressed that they were not interested in participating.

\begin{tabular}{ll}
\multicolumn{2}{l}{ Table I Characteristics of the study population } \\
\hline Characteristic & $\mathbf{n}(\%) /$ mean (SD) \\
\hline Age of the mother (years) & \\
I6-22 & $23(6.6)$ \\
$23-32$ & $184(52.6)$ \\
$33-42$ & $143(40.9)$ \\
Geographical origin & \\
Beirut & $135(38.6)$ \\
Mount Lebanon & $215(61.4)$ \\
Body mass index before pregnancy & \\
Underweight & $10(2.9)$ \\
Normal weight & $243(69.4)$ \\
Overweight & $69(19.7)$ \\
Obese & $13(3.7)$ \\
Education level & \\
Uneducated & $46(13.1)$ \\
Primary cycle & $15(4.3)$ \\
Secondary cycle & $90(25.7)$ \\
University education & $199(56.9)$ \\
Occupation & \\
No professional activity & $204(58.3)$ \\
Professional activity & $146(41.7)$ \\
First pregnancy & $137(39.1)$ \\
Type of delivery & \\
Cesarean section & $181(51.7)$ \\
Normal route & $169(48.3)$ \\
Medical problem during pregnancy & \\
Anemia & $47(13.4)$ \\
Hypertension & $5(1.4)$ \\
Gestational diabetes & $18(5.1)$ \\
Thyroid problem & $3(0.9)$ \\
Depression & $3(0.9)$ \\
Weight gain during pregnancy, mean (SD) & $12.84(4.76)$ \\
Number of live children, mean (SD) & $1.94(1.05)$ \\
Delivery period in weeks, mean (SD) & $39.3(1.05)$ \\
\hline Abbrevation: SD, stat &
\end{tabular}

Abbreviation: SD, standard deviation. 
Table 1 describes the general characteristics of the 350 women recruited from Beirut and Mount Lebanon. The interviewed women were aged between 16 and 42 years. Most of them (69.4\%) had a normal mean of BMI and a university degree; $21.7 \%$ of participants reported medical problems, mainly anemia. The delivery term was 39.3 weeks ( standard deviation $=1.05)$.

\section{Characteristics and outcome of the neonates}

Table 2 shows the characteristics of neonates. Of the 350 neonates included in our study, 50.9\% were males. Most of them had a normal weight, whereas $13.4 \%$ were underweight. Cranial perimeter was unmeasured in $74 \%$ of neonates. Congenital malformations were detected in two neonates, and 16 neonates were transferred to the NCU due to medical problems. The means of the Apgar score done 5 and 10 minutes after delivery were 8.49 and 9.66 , respectively.

\section{Exposure to drugs and supplements, and behavior during pregnancy}

Figure 1 describes drug, supplement, and toxic substance use during pregnancy. Most of the women in our study were taking such supplements as iron (76.90\%), folic acid (66.90\%), multiple vitamins (66\%), and calcium (48.9\%). A total of 259 (74\%) women reported drinking caffeinated beverages during pregnancy, whereas only $1.1 \%$ of them drank alcohol. However, $47.5 \%$ declared being exposed to smoking: $32 \%$ were exposed to passive smoking, $6.3 \%$ were

Table 2 Characteristics and outcome of the neonates

\begin{tabular}{ll}
\hline Characteristic & $\mathbf{n}(\%) /$ mean (SD) \\
\hline Sex of the baby & $178(50.9)$ \\
$\quad$ Male & $172(49.1)$ \\
$\quad$ Female & \\
Weight of the baby (g) & $276(78.9)$ \\
$\quad$ Normal weight: $2750-3750$ & $47(13.4)$ \\
Underweight: $<2750$ & $27(7.7)$ \\
Overweight: $>3750$ & \\
Cranial perimeter $(\mathrm{cm})$ & $9(2.6)$ \\
$<34$ cm & $74(21.1)$ \\
$34-36$ & $8(2.3)$ \\
$>36$ & $259(74)$ \\
Not measured & $2(0.6)$ \\
Congenital malformation & $16(4.6)$ \\
Medical problem that required transfer & \\
to the neonatal care unit & $49.17(2.7 \mathrm{I})$ \\
Height of the baby in cm, mean (SD) & $8.49(0.99)$ \\
Apgar score at 5 minutes, mean (SD) & $9.66(0.63)$ \\
Apgar score at 10 minutes, mean (SD) &
\end{tabular}

Abbreviation: SD, standard deviation. active cigarette smokers, and 8.3\% were water-pipe smokers. Among drugs, category $\mathrm{B}$ and $\mathrm{C}$ drugs were the most taken, with $72.9 \%$ and $34.9 \%$, respectively, while category D represented $10.6 \%$ and there was a very low percentage for category X drugs $(0.3 \%)$.

In bivariate analysis, education level was not associated with substance and drug consumption, except for active smoking, which was significantly less common in universityeducated women versus others $(9.5 \%$ versus $25 \%$, $P<0.001)$. Women aged 33 years and older consumed significantly more alcohol and drugs of categories B and D than younger women $(P<0.05)$; however, no significant differences were observed between geographical regions $(P>0.05)$ (results not shown).

\section{Multivariate analyses}

In order to test the effect of different sociodemographic and clinical characteristics as well as different behaviors during pregnancy on neonates' medical problems, development and on the risk of having underweight babies, logistic regression models were used (Table 3).

We found that active tobacco smoking was significantly associated with an elevated risk of medical problems $(P<0.047)$; babies born from tobacco-smoking mothers had approximately three times more risk of having medical problems requiring NCU transfer. Coffee consumption may also be strongly associated with neonatal medical problems (adjusted odds ratio $[A O R]=4.37$ ). As expected, we also noticed that having a late delivery is highly associated with a decrease in the risk of neonates developing medical problems, or having underweight babies $(P<0.001)$.

We observed that consuming category $\mathrm{C}$ drugs ( $\mathrm{AOR}=2.01$, confidence interval 1.06-4.02) or being a passive smoker $(\mathrm{AOR}=2.2$, confidence interval $=1.13-4.31$ ) were significantly associated with increased risk of having underweight babies. Active tobacco smoking was associated with a higher risk of underweight babies $(\mathrm{AOR}>1)$, but the results did not reach statistical significance $(P=0.151)$.

Concerning the relationship between the Apgar score and drug and other substance use during pregnancy, we found that higher frequencies of weekly water pipe and of daily cigarette pack consumption were associated with a lower Apgar score at 5 or 10 minutes. The exposure to category D drugs during pregnancy was also significantly related to a smaller Apgar 10. In addition, we found that having gestational diabetes was negatively associated with 


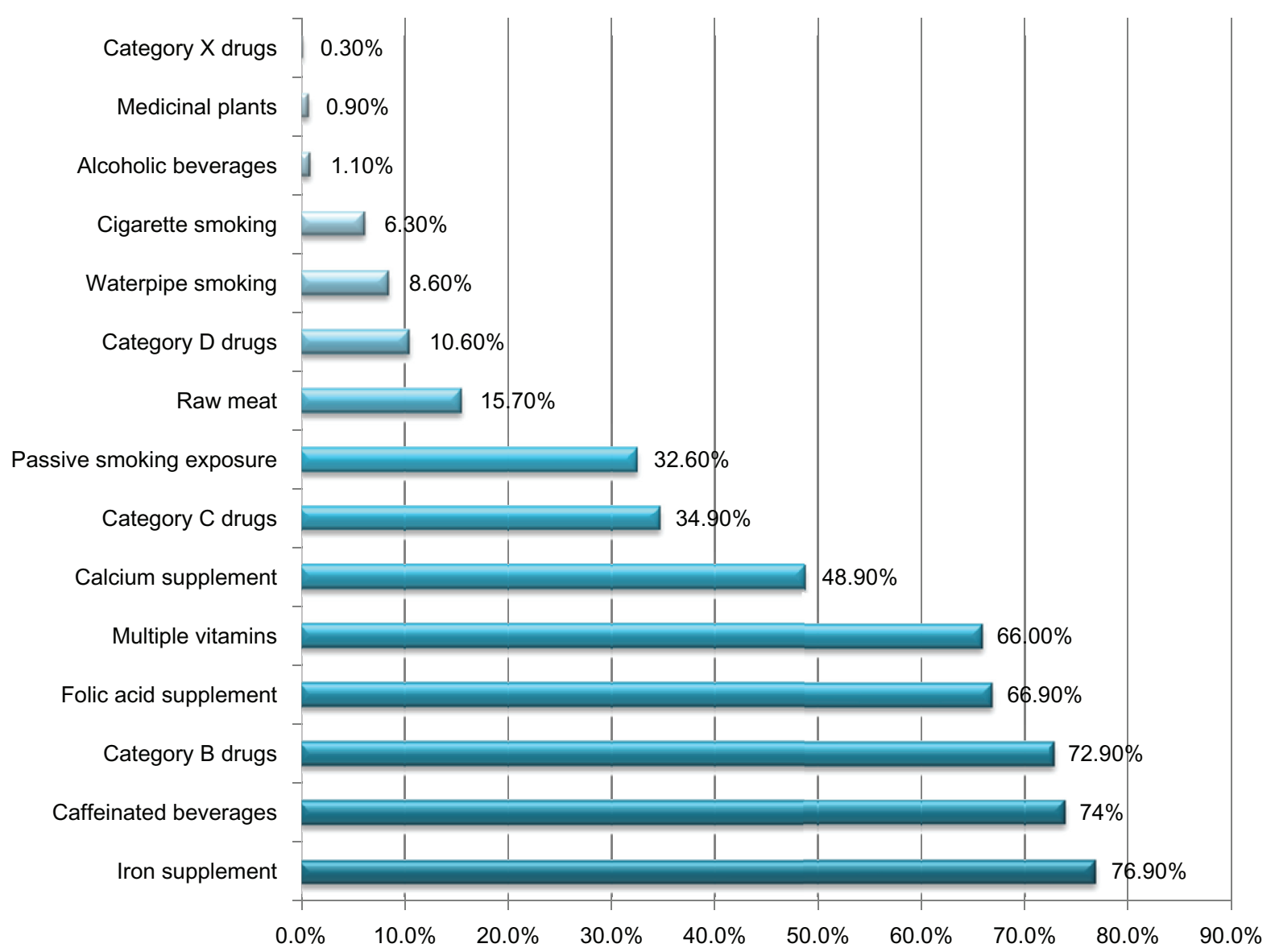

Figure I Exposure to drugs, supplements, and risky behaviors during pregnancy of Lebanese women $(\mathrm{n}=350)$.

Apgar score. Finally, exposure to category $\mathrm{X}$ drugs may negatively affect the Apgar $5(P=0.07)$ (Table 4).

\section{Discussion}

Our study evaluated the exposure of pregnant Lebanese women to risky substances and their influence on birth outcomes. We noticed that the participants were exposed to multiple factors that may affect the neonates' health. Indeed, most of them drank caffeinated beverages (75\%), while substantial proportions were exposed to smoking (active and passive, cigarette and water pipe), alcohol, and drugs. Our results are more or less similar to those of others for coffee, ${ }^{20,21}$ smoking, ${ }^{22,23}$ alcohol,,${ }^{24}$ and drugs. ${ }^{25,26}$ For active smoking, they are lower than those of Chaaya and collaborators, ${ }^{12}$ probably due to the higher education level of our population.

The high consumption of caffeinated beverages is not surprising, given that the use of caffeinated substances is not forbidden by doctors during pregnancy, since reports about its harm on the fetus are scant and inconclusive, ${ }^{27}$ as opposed to alcohol or tobacco consumption. It is troubling, however, given that coffee consumption was associated with higher risk of neonates' medical problems with a tendency to significance $(P=0.064)$; in fact, the occurrence of congenital malformations, fetal growth retardation, smallfor-date babies, miscarriages (spontaneous abortions), behavioral effects, and maternal fertility problems that presumably resulted from caffeine consumption have all been reported. ${ }^{28}$ In a Danish study of 7346 pregnant women, authors found that consumption of coffee during pregnancy was associated with a higher risk of fetal death, especially losses occurring after 20 completed weeks of gestation. ${ }^{29}$ The increased risk was linked to various adverse pregnancy outcomes, including fetal loss, birth defects, fetal growth retardation, and increased number of uterine contraction peaks. Thus, coffee consumption during pregnancy has been subject to preventive action in some countries, ${ }^{30}$ and was recommended to be restricted by several researchers. ${ }^{31,32}$ On the other hand, the trend we found may be due to the fact that caffeine is present at different concentrations in many beverages, including coffee, tea, and colas, as well as chocolate, and in our study we did not differentiate and 
Table 3 Multivariate analyses for neonatal outcomes: logistic regressions

\begin{tabular}{|c|c|c|c|c|}
\hline \multirow[t]{2}{*}{ Characteristics } & \multirow[t]{2}{*}{ OR $(95 \% \mathrm{Cl}), \mathrm{P}$-value } & \multicolumn{3}{|c|}{ Model used } \\
\hline & & AOR & $95 \% \mathrm{Cl}$ & P-value \\
\hline \multicolumn{5}{|c|}{ Dependent variable: neonate medical problem requiring neonatal intensive care unit transfer* } \\
\hline Later delivery month & $0.19(0.08-0.45),<0.001$ & 0.21 & $0.087-0.494$ & $<0.001$ \\
\hline Caffeinated consumption & $7.46(1.68-33.33), 0.008$ & 4.37 & $0.92-20.87$ & 0.064 \\
\hline Tobacco smoking & $0.27(1.29-10.75), 0.015$ & 3.26 & $1.02-10.49$ & 0.047 \\
\hline Mother education & 0.60 (0.53-2.37), 0.468 & 0.57 & $0.11-3.10$ & 0.519 \\
\hline \multicolumn{5}{|c|}{ Dependent variable: underweight baby $(<2750 \mathrm{~g}) * *$} \\
\hline Later delivery month & $0.20(0.08-0.5 \mathrm{I}), 0.00 \mathrm{I}$ & 0.22 & $0.09-0.50$ & $<0.001$ \\
\hline Tobacco smoking & $0.44(0.21-0.93), 0.030$ & 1.79 & $0.8 \mathrm{I}-3.96$ & 0.151 \\
\hline Category $\mathrm{C}$ drug & $2.15(1.16-4.00), 0.016$ & 2.06 & $1.06-4.02$ & 0.034 \\
\hline Passive smoking & $2.23(1.20-4.16), 0.01 \mathrm{I}$ & 2.20 & $1 .|3-4.3|$ & 0.021 \\
\hline Mother education & $0.84(0.36-1.98), 0.696$ & 1.40 & $0.52-3.77$ & 0.504 \\
\hline
\end{tabular}

Notes: *Nagelkerke $R^{2}=0.252$, Hosmer-Lemeshow $P=0.477,95.5 \%$ correctly classified; $* *$ Nagelkerke $R^{2}=0.289$, Hosmer-Lemeshow $P=0.568,94.3 \%$ correctly classified. Collinearity absence was verified. Independent variables entered in the initial model were age of the mother, geographical origin, body mass index before pregnancy, education level, occupation, parity, delivery type, medical problem types during pregnancy (anemia, hypertension, gestational diabetes), weight gain during pregnancy, number of live children, delivery term, and exposure to medications and licit substances.

Abbreviations: $\mathrm{Cl}$, confidence interval; OR, unadjusted odds ratio; AOR, adjusted odds ratio.

divide our analysis into the types of caffeinated beverages, but took all in at once. Additional studies will be necessary to confirm these effects.

Several other associations of substance use during pregnancy emerged from this study: our results showed a significant association between mothers' tobacco smoking and elevated risk of medical problems. Indeed, babies born from tobacco-smoking mothers had approximately three times more risk of having medical problems requiring NCU transfer. Paralleling our results, numerous studies have shown strong associations between maternal cigarette smoking and neonatal morbidity and mortality. ${ }^{33-35}$ In other studies, smoking was recognized as a major risk factor for poor birth outcomes that needed transfer to the NCU. ${ }^{36}$ Furthermore, some researchers found that maternal smoking was associated with an increased risk of sudden infant death syndrome. Król and collaborators confirmed that active smoking during pregnancy had a negative effect on the cerebral mass of the neonate; the deficiency in cerebral mass increased with greater smoking intensity. ${ }^{37}$ The risk to the developing fetus seems primarily due to the nicotine: the biological mechanisms of how nicotine affects fetal development have been examined in extensive human and laboratory studies, which showed that nicotine crosses the placenta and targets specific neurotransmitter receptors in the fetal brain, eliciting abnormal cell proliferation and increasing susceptibility to hypoxia-induced brain damage. ${ }^{3,38}$ In addition, we demonstrated, consistently with other research, ${ }^{30}$ that babies born

Table 4 Multivariate analyses for neonatal outcomes: multiple linear regressions

\begin{tabular}{|c|c|c|c|c|c|}
\hline \multirow[t]{2}{*}{$\overline{\text { Characteristics }}$} & \multirow[t]{2}{*}{ Unadjusted beta $(95 \% \mathrm{Cl}), \mathrm{P}$-value } & \multirow{2}{*}{$\begin{array}{l}\text { Unstandardized } \\
\text { adjusted beta }\end{array}$} & \multicolumn{3}{|l|}{ Model used } \\
\hline & & & $95 \% \mathrm{Cl}$ & $P$-value & $\begin{array}{l}\text { Standardized } \\
\text { adjusted beta }\end{array}$ \\
\hline \multicolumn{6}{|c|}{ Dependent variable: logarithm of Apgar score at 5 minutes* } \\
\hline Daily cigarette packs & $-0.016(-0.027$ to -0.006$), 0.003$ & -0.040 & -0.059 to -0.022 & $<0.001$ & -0.213 \\
\hline Weekly water pipes & $-0.010(-0.017$ to -0.002$), 0.011$ & -0.034 & -0.047 to -0.021 & $<0.001$ & -0.268 \\
\hline Category D drug & $-0.036(-0.061$ to -0.012$), 0.004$ & -0.037 & -0.079 to 0.005 & 0.082 & -0.088 \\
\hline Category $X$ drug & $-0.068(-0.212$ to 0.075$), 0.35 \mathrm{I}$ & -0.227 & -0.470 to 0.018 & 0.070 & -0.093 \\
\hline Gestational diabetes & $-0.057(-0.091$ to -0.022$), 0.00 \mathrm{I}$ & -0.120 & -0.179 to -0.06 & $<0.001$ & -0.198 \\
\hline \multicolumn{6}{|c|}{ Dependent variable: logarithm of Apgar score at 10 minutes* } \\
\hline Daily cigarette packs & $-0.036(-0.055$ to -0.017$),<0.001$ & -0.017 & -0.028 to -0.006 & 0.002 & -0.165 \\
\hline Weekly water pipes & $-0.036(-0.049$ to -0.023$),<0.001$ & -0.010 & -0.017 to -0.002 & 0.010 & -0.137 \\
\hline Gestational diabetes & $-0.116(-0.178$ to -0.055$),<0.001$ & -0.055 & -0.089 to -0.020 & 0.002 & -0.163 \\
\hline Category D drug & $-0.056(-0.101$ to -0.011$), 0.014$ & -0.029 & -0.054 to -0.005 & 0.019 & -0.125 \\
\hline
\end{tabular}

Notes: *Apgar 5-minute $R^{2}=0.182$, Apgar 10-minute $R^{2}=0.093$. Collinearity absence was verified. Independent variables entered in the initial model were age of the mother, geographical origin, body mass index before pregnancy, education level, occupation, parity, delivery type, medical problem types during pregnancy (anemia, hypertension, gestational diabetes), weight gain during pregnancy, number of live children, delivery term, and exposure to medications and licit substances.

Abbreviation: $\mathrm{Cl}$, confidence interval. 
to women who smoked a water pipe during pregnancy had a higher proportion of immediate need for extra medical or emergency care. For active cigarette smoking, although we found a relationship between active smoking and underweight, the relationship we found did not reach statistical significance, probably due to the low prevalence of active smokers or the low smoking dose.

Similarly, we found a doubling of the risk of underweight in babies of women who were exposed to passive smoking; this is consistent with other studies in which high environmental tobacco-smoke exposure was associated with low birth weight, preterm birth, and most strongly preterm birth. ${ }^{39}$ On average, birth weight was reduced by 120 g per pack of cigarettes (or cigar/pipe equivalent) smoked daily by the father. ${ }^{40}$

Alcohol use was much less reported during pregnancy than other substances $(1.1 \%)$ in this study. In contrast to other reports, ${ }^{15,16}$ we did not find any association with postnatal outcomes. This is due to the low number of pregnant women that were reported drinking alcohol during their pregnancy.

Another important risk factor was the exposure to drugs. Our participants seemed to be consuming medications belonging to categories $\mathrm{B}(72.9 \%)$ and $\mathrm{C}(34.9 \%)$, whereas category D $(10.6 \%)$ and $\mathrm{X}(0.3 \%)$ drugs were much less taken. This indicates that pregnant Lebanese women may have been more likely to stay away from the most dangerous drug categories ( $\mathrm{D}$ and $\mathrm{X}$ ), as might have been recommended by their doctor and/or pharmacist. Other explanations would be that they may have less access to or need of these drugs, in addition to social desirability in responding, or, they may be underreporting these drugs for fear of legal consequences of disclosing this information. However, we think that the latter explanations are less likely, and we doubt that Lebanese women are aware of the classification of drugs during pregnancy. Nevertheless, confirmation of drug use with urine samples would have given more credibility to prevalence rates; further studies are suggested to take into account this last point.

Our results are however similar to those of other countries: for instance, about two-thirds of women in the US take one or more prescription medications during pregnancy. Nevertheless, it was found that more that $90 \%$ of the medications approved by the FDA from 1980 to 2000 had insufficient data to determine safety in pregnancy. ${ }^{41}$ In addition, in a national study done in Brazil on 610 pregnant women, results were similar to ours, and category D and X drugs were taken during pregnancy in low percentages. ${ }^{42}$ Furthermore, in the multivariate analysis, the use of these medications dur- ing pregnancy was associated with the newborn's status in several ways: category $\mathrm{C}$ medication intake was associated with underweight birth, while the use of D- and X-category drugs were associated with increased risk of immediate need for intensive care.

There are several limitations to the current analysis that warrant mentioning. First, a selection bias is possible, since we worked with women who delivered in university tertiary care hospitals of the capital and surroundings; they may not represent the childbearing Lebanese population, particularly those of lower socioeconomic status from remote areas. We expect our results to be underestimating the true prevalence of exposure to toxic substances during pregnancy. Moreover, the data are cross-sectional, and therefore no causal relationships can be inferred; analytical results are presented indicatively.

Second, the risk of developing birth defects depends on exposure, timing, dosing, and route of administration; ${ }^{2}$ this information was missing from our data, and while reporting substance use for analysis, there was no specification of timing of exposure, dose, or route of administration for these substances. Therefore, we were not able to adjust our model on timing or dosage. In fact, we did not collect information about these factors because of probable nondifferential memory bias; this may lead to crucial differences in results between using substances in the first trimester and afterwards. The information bias could also be differential, women with children who had health problems being more able to remember exposures than women with healthy children; this bias is expected to induce false-positive associations.

Third, a medical problem that occurred in newborns was not detailed because of the low number of babies that had such a problem, which precluded detailed analysis, and we could not perform any analysis on congenital malformations since only two cases were found. Finally, a confounding bias is possible, since we may not have taken all potential confounders into account or the sample size may have precluded showing some associations. For example, although anemia would be expected to affect birth weight, it was removed from the final model in our study; this may be due to an underpowering of our sample size or to a low severity of anemia, given particularly that the majority of women were taking iron supplements. Although larger-scale studies may be necessary to adjust or confirm our analytical results, we do not expect that drastic changes in essential results would occur, especially concerning substantial levels of exposure to some substances and medications. 


\section{Conclusion}

Our study demonstrated that Lebanese women were exposed during pregnancy to medications and licit substances that affected neonates' health. Some risk factors associated with neonatal medical problems were identified, including active tobacco smoking and coffee consumption. Consuming category $\mathrm{C}$ drugs or being a passive smoker was associated with increased risk of having underweight babies. Higher weekly water-pipe exposure, number of daily cigarette packs, or exposure to category D drugs during pregnancy were associated with a lower Apgar score. Our findings have implications for clinical obstetric practice and prevention and intervention programs: clinicians should screen all pregnant women for smoking, exposure to caffeine, and other substance use and give them appropriate advice and explain all risks that may develop while using these substances.

\section{Disclosure}

The authors report no conflicts of interest in this work.

\section{References}

1. Ngoc NT, Merialdi M, Abdel-Aleem H, et al. Causes of stillbirths and early neonatal deaths: data from 7993 pregnancies in six developing countries. Bull World Health Organ. 2006;84:699-705.

2. Food and Drug Administration. Reviewer Guidance: Evaluating the risks of drug exposure in human pregnancies. 2005. Available from: http:/www.fda.gov/downloads/Drugs/.../Guidances/ucm071645.pdf. Accessed April 18, 2013.

3. Rogers JM, Kavlock RJ. Developmental toxicology. In: Klaassen CD, editor. Casarett and Doull's Toxicology: The Basic Science of Poisons. 5th ed. Blacklick (OH): McGraw-Hill; 1996:301-331.

4. Schardein JL. Chemically Induced Birth Defects. 3rd ed. New York: Marcel Dekker; 2000.

5. Di Franza JR, Lew RA. Effect of maternal cigarette smoking on pregnancy complications and sudden infant death syndrome. J Fam Pract. 1995;40:385-394.

6. Royal College of Physicians. Effects of maternal active and passive smoking on fetal and reproductive health. In: Britton J, Edwards R, editors. Passive Smoking and Children: A Report by the Tobacco Advisory Group of the Royal College of Physicians. London: Royal College of Physicians; 2010:40-76.

7. Shah NR, Bracken MB. A systematic review and meta-analysis of prospective studies on the association between maternal cigarette smoking and preterm delivery. Am J Obstet Gynecol. 2000; $182: 465-472$.

8. US Surgeon General, Department of Health and Human Services. The Health Consequences of Smoking: A Report of the US Surgeon General. Rockville: DHHS; 2004.

9. US Surgeon General, Department of Health and Human Services. Women and Smoking: A Report of the US Surgeon General. Rockville: DHHS; 2001.

10. Office for National Statistics (National Congenital Anomaly System). Congenital Anomaly Statistics: Notifications England and Wales 2008. Series MB3, no 23. Newport, UK: ONS; 2010.

11. Tong VT, Jones JR, Dietz PM, D’Angelo D, Bombard JM; Centers for Disease Control and Prevention (CDC). Trends in smoking before, during, and after pregnancy - Pregnancy Risk Assessment Monitoring System (PRAMS), United States, 31 sites, 2000-2005. MMWR Surveill Summ. 2009;58:1-29.
12. Chaaya M, Jabbour S, El-Roueiheb Z, Chemaitelly H. Knowledge, attitudes, and practices of argileh (water pipe or hubble-bubble) and cigarette smoking among pregnant women in Lebanon. Addict Behav. 2004;29:1821-1831.

13. Ventura SJ, Martin JA, Taffel S, et al. Advanced report of final natality statistics, 1993. Month Vital Stat Rep. 1995;44:1-88.

14. Dlugosz L, Bracken MB. Reproductive effects of caffeine (a review and theoretical analysis). Epidemiol Rev. 1992;14:83-100.

15. Andersen AM, Andersen PK, Olsen J, Grønbæk M, Strandberg-Larsen K. Moderate alcohol intake during pregnancy and risk of fetal death. Int J Epidemiol. 2012;41:405-413.

16. Stratton K, Howe C, Battaglia F. Fetal Alcohol Syndrome: Diagnosis, Epidemiology, Prevention, and Treatment. Washington: National Academy Press; 1996

17. Ganga-Zandzou PS, Moussaou D, Chani M, Hamzaoui S, L'Kassimi H, Bongo ELS. Fiabilité et utilité du score d'Apgar. Arch Pediatr. 2002;9:874-875.

18. Food and Drugs Administration. FDA pregnancy categories. Available from: http://depts.washington.edu/druginfo/Formulary/Pregnancy.pdf. Accessed April 18, 2013.

19. Medline Plus. APGAR. Available from: http://www.nlm.nih.gov/ medlineplus/ency/article/003402.htm. Accessed April 18, 2013.

20. Conde A, Teves C, Figueiredo B. Maternal coffee intake and associated risk factors: effects on fetal growth and activity. Acta Med Port. 2011;24:241-248.

21. Browne ML, Hoyt AT, Feldkamp ML, et al. Maternal caffeine intake and risk of selected birth defects in the National Birth Defects Prevention Study. Birth Defects Res A Clin Mol Teratol. 2011;91:93-101.

22. Barbour B, Salameh P, Ziadeh F. Tabagisme chez les mères libanaises: connaissances, attitudes et pratiques. East Mediterr Health J. 2006;12: 405-416.

23. Hoff GL, Okah FA, Cai J, Liu Y. Smoking during pregnancy rates trends in a high smoking prevalence state, 1990-2009. South Med J. 2012;105:636-644.

24. Maalouf D, El Hachem H, Kesrouani A, et al. Awareness and knowledge about risks of drinking during pregnancy in pregnant Lebanese women. Encephale. 2011;37:94-100. French.

25. Samaha I, Rady M, Nabhan A, Gadallah M. The prevalence of congenital malformations at birth in Ain Shams University Maternity Hospital Cairo, Egypt, 1994. J Egypt Public Health Assoc. 1995;70: 595-608.

26. Al-Riyami IM, Al-Busaidy IQ, Al-Zakwani IS. Medication use during pregnancy in Omani women. Int J Clin Pharm. 2011;33:634-641.

27. Loomans EM, Hofland L, van der Stelt O, et al. Caffeine intake during pregnancy and risk of problem behavior in 5- to 6-year-old children. Pediatrics. 2012;130:e305-e313.

28. Christian MS, Brent RL. Teratogen update: evaluation of the reproductive and developmental risks of caffeine. Teratology. 2001;64:51-78.

29. Danish Coffee Information. The ten most coffee drinking nations, 2005. Copenhagen: Danish Coffee Information; 2005. Danish.

30. Nuwayhid IA, Yamout B, Azar G, Kambris MA. Narghile (hubblebubble) smoking, low birth weight, and other pregnancy outcomes. Am J Epidemiol. 1998;148:375-383.

31. Adén U. Methylxanthines during pregnancy and early postnatal life. Handb Exp Pharmacol. 2011;200:373-389.

32. Kuczkowski KM. Peripartum implications of caffeine intake in pregnancy: is there cause for concern? Rev Esp Anestesiol Reanim. 2009;56:612-615.

33. Cliver SP, Goldenberg RL, Cutter GR, Hoffman HJ, Davis RO, Nelson KG. The effect of cigarette smoking on neonatal anthropometric measurements. Obstet Gynecol. 1995;85:625-630.

34. Wen SW, Goldenberg RL, Cutter GR, et al. Smoking, maternal age, fetal growth, and gestational age at delivery. Am J Obstet Gynecol. 1990;162:53-58.

35. Taylor B, Wadsworth J. Maternal smoking during pregnancy and lower respiratory tract illness in early life. Arch Dis Childhood. 1987; 62:786-791. 
36. Stankaitis JA, Brill HR, Walker DM. Reduction in neonatal intensive care unit admission rates in a Medicaid managed care program. Am J Manag Care. 2005;11:166-172.

37. Król M, Florek E, Piekoszewski W, Bokiniec R, Kornacka MK. The impact of intrauterine tobacco exposure on the cerebral mass of the neonate based on the measurement of head circumference. Brain Behav. 2012;2:243-248

38. Andres RL, Day MC. Perinatal complications associated with maternal tobacco use. Semin Neonatol. 2000;5:231-241.

39. Windham GC, Hopkins B, Fenster L, Swan SH. Prenatal active or passive tobacco smoke exposure and the risk of preterm delivery or low birth weight. Epidemiology. 2000;11:427-433.
40. Rubin DH, Krasilnikoff PA, Leventhal JM, Weile B, Berget A. Effect of passive smoking on birth-weight. Lancet. 1999;328:415-417.

41. Adam MP, Polifka JE, Friedman JM. Evolving knowledge of the teratogenicity of medications in human pregnancy. Am J Med Genet C Semin Med Genet. 2011;157:175-182.

42. Guerra GC, da Silva AQ, França LB, Assunção PM, Cabral RX, Ferreira AA. Drug use during pregnancy in Natal, Brazil. Rev Bras Ginecol Obstet. 2008;30:12-18.

\section{Publish your work in this journal}

Drug, Healthcare and Patient Safety is an international, peer-reviewed open-access journal exploring patient safety issues in the healthcare continuum from diagnostic and screening interventions through to treatment, drug therapy and surgery. The journal is characterized by the rapid reporting of reviews, original research, clinical, epidemiological and

\section{Dovepress}

post-marketing surveillance studies, risk management, health literacy and educational programs across all areas of healthcare delivery. The manuscript management system is completely online and includes a very quick and fair peer-review system. Visit http://www.dovepress.com/ testimonials.php to read real quotes from published authors.

Submit your manuscript here: http://www.dovepress.com/drug-healthcare-and-patient-safety-journal 